\title{
NEON to shed light on environment research
}

\section{San Diego}

Ten sites across the United States are to be linked in a network that will provide researchers with a continuous ecological health check. The National Science Foundation (NSF) is in the final stages of planning a \$100 million National Ecological Observatory Network (NEON), which aims to provide a computerized instrumentation infrastructure for decades of environmental research.

Last week, at the University of California at San Diego, ecologists, biologists, computer scientists and systematists met to refine plans for NEON. They see the network as a system that would provide an unprecedented real-time picture of ecological systems, recording data on biodiversity and climate and integrating this with data from other studies, including genomics, soil chemistry and hydrology.

"This is a once-in-a-career opportunity to create an infrastructure for ecology," says Jim Beach, assistant director for informatics at the University of Kansas' Natural History Museum. Late last year, the National Science Board, which governs the NSF, approved the NEON concept in the agency's budget for long-term infrastructure projects. This is the first time the NSF's biological division has had such a major equipment budget request; previously, such largesse has been the exclusive domain of disciplines like physics and astronomy.

After the first NEON workshop in January in Florida, a group of 26 academic researchers and four NSF officials issued a report, saying: "The goal of NEON is to develop distributed infrastructure for environmental biology, ranging from molecular genetics to landscape-level study. The infrastructure should advance the study of continental- and regional-scale issues."

Last week, more than 30 meeting participants discussed the equipment needed to make NEON a successful scientific system. Field biologists, for instance, want inexpensive wireless systems for data transmission from field sites to a central network, digital field guides on species and remote access to centralized instruments - including microarrays for genomic studies, mass spectrometers and high-performance computers.

Each observatory will cost around $\$ 10$ million to create, and NSF officials say they will provide \$1 million a year in operational funds for each facility. The agency also

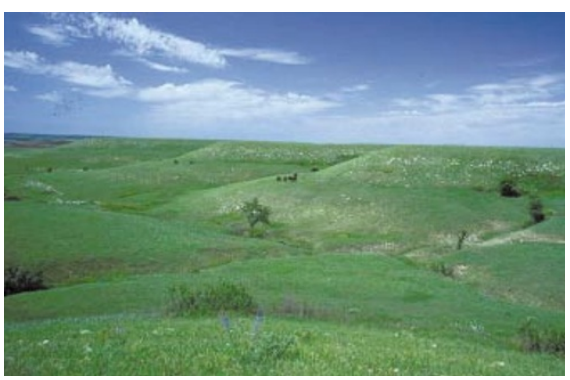

Field work: Konza Prairie, one of the LTER sites that could be included in NEON. expects to have a pool of research funds - the amount has yet to be determined - for proposals for research through NEON. Once in place, the observatories should operate for 30 years.

NEON funding is now included in the Clinton Administration's budget proposal for the 2001 fiscal year that begins in October. Congress still has to approve the funding, and building the entire network will require a spending package spread over 6 years.

In the initial round of the competitive process for NEON designation, later this year, NSF officials aim to fund three observatories. The next round, probably in 2001, will designate four more observatories, and the final three observatories will be picked sometime after that. Bids are expected to come from consortia of universities, museums and research institutes.

At the workshop last week, participants urged the NSF to include other ecological facilities in the consortia - such as the 24 Long-Term Ecological Research (LTER) facilities already supported by the NSF, plus survey sites run by the US Geological Survey sites and the US Forest Service.

The birth of NEON comes after more than a year of prior planning and workshops on a related NSF concept called the Biodiversity Observatory Network. This aimed to monitor a range of sites in each major region of the United States, but lacked the NEON's emphasis on networking. Last year, however, NSF officials decided that NEON should proceed first.

Rex Dalton

\section{Are AIDS dissidents advising South Africa?}

\section{Cape Town}

Leading AIDS dissident David Rasnick has claimed that Thabo Mbeki, the president of South Africa, requested his scientific opinion on eight questions related to HIV and AIDS last January.

Rasnick is one of a small band of scientists who claim that HIV does not cause AIDS. Mainstream AIDS researchers are deeply concerned at the suggestion that he is advising the South African government.

Mbeki has also allegedly put the same questions to health minister Manto Tshabalala-Msimang, who has caused concern by refusing to clarify whether she accepts that HIV is the cause of AIDS.

Rasnick has posted the text of what he claims are Mbeki's questions on the 'Virusmyth' website (www.virusmyth.com), along with his reply, co-written with another AIDS dissident, the historian Charles Geshekter of California State University.
According to Rasnick, Mbeki wants to provide a public forum where proponents and critics of the HIV hypothesis can present the evidence for and against the assertions that AIDS is contagious and sexually transmitted, that HIV causes AIDS, and that anti-HIV drugs help people with the disease.

Rasnick further claims that Mbeki is asking other world leaders, including US president Bill Clinton, UK prime minister Tony Blair, and German chancellor Gerhard Schroeder, to join him in a discourse about these issues. Rasnick's Internet posting coincided with an announcement by Tshabalala-Msimang on the establishment of a panel of experts to investigate various aspects of AIDS (see Nature 404, 115; 2000).

With Peter Duesberg, his colleague at the University of California, Berkeley, Rasnick co-authored an article entitled "The AIDS dilemma: drug diseases blamed on a passenger virus", published in the journal
Genetica in 1998. Duesberg has confirmed that he has not been asked to sit on Tshabalala-Msimang's panel, but says he has written to Mbeki confirming his stand on the HIV-AIDS hypothesis. He indicated to Nature that Rasnick had been approached to participate on the panel.

Tshabalala-Msimang is coming under increasing pressure for her unorthodox views on AIDS. She was booed by angry activists at a dinner in Durban last week, at which, referring to the use of antiretroviral drugs, she said that she didn't want to "plunge into something I don't understand".

This followed a stinging attack by the acting Constitutional Court judge Edwin Cameron, who is HIV-positive. Cameron criticized the government's policies on AIDS as causing "considerable grief and confusion", and also questioned Tshabalala-Msimang's competence as a minister.

Michael Cherry 